\title{
ANÁLISE DA EVOLUÇÃO DAS ATIVIDADES DE INVESTIMENTO NO FLUXO DE CAIXA DE EMPRESAS DO SETOR DE TELECOMUNICAÇÕES
}

\author{
Nome: Carlos Eduardo de Oliveira \\ Instituição: Universidade Federal de Uberlândia (UFU) \\ E-mail: carlos.oliveira@ufu.br \\ Nome: Carolina Parreira da Silva \\ Instituição: Universidade Federal de Uberlândia (UFU) \\ E-mail: carolina.parreira@ outlook.com
}

\section{Nome: Aparecida Lima}

Instituição: Federal de Uberlândia (UFU)

E-mail: carolinececilia1@ hotmail.com

\section{Nome: Lorraine Alves Fernandes}

Instituição: Universidade Federal de Uberlândia (UFU)

E-mail: lorraineaf22@gmail.com

\section{Nome: Fernando Souza de Oliveira}

Instituição: Universidade Federal de Uberlândia (UFU)

E-mail: fernandosouzza@outlook.com

\section{RESUMO}

O objetivo do estudo foi verificar a evolução das atividades de investimento, apresentadas no Fluxo de Caixa, das empresas do setor de telecomunicações, listadas na B3. Esta pesquisa descritiva realizou coleta de dados no site da B3, das Demonstrações dos Fluxos de Caixa no período de 2013 a 2015. Os principais resultados apontam que (1) em relação aos valores das atividades de investimento, pode-se inferir que os maiores investimentos foram realizados pelas empresas Telefônica, Oi e Tim; (2) a Telefônica, Telebrás e Oi foram as que apresentaram as maiores evoluções relativas (\%), (3) verificou-se evolução dos investimentos do setor; (4) as empresas aumentaram os gastos em atividades de investimento, isso demonstra o interesse pela evolução dos serviços prestados aos consumidores, bem como uma necessidade de atuar de forma competitiva em um mercado de acirrada concorrência.

Palavras-chave: Gestão Financeira. Fluxo de Caixa. Setor de Telecomunicações.

\begin{abstract}
The objective of the study was to verify the evolution of investment activities, presented in the Cash Flow, of the companies in the telecommunications sector, listed in B3. This descriptive research carried out data collection on the B3 website, the Cash Flow Statements from the period between 2013 and 2015. The main results indicate that (1) in relation to the values of investment activities, it can be inferred that the largest investments were made by the companies Telefônica, Oi and Tim; (2) Telefônica, Telebrás and Oi were the ones that presented the biggest relative evolutions (\%), (3) there was an evolution of investments in the sector; (4) companies have increased spending on investment activities, this demonstrates the
\end{abstract}




\section{Contabilidade}

interest in the evolution of services provided to consumers, as well as a need to act competitively in a market of fierce competition.

Keywords: Financial Management. Cash flow. Telecommunications industry.

\section{INTRODUÇÃO}

É fundamental que exista comunicação entre as pessoas, que podem se utilizar de diversos instrumentos para isso, principalmente, atualmente, por conta dos avanços tecnológicos. O setor de telecomunicações necessita ficar atento a esses avanços para que possam disponibilizar, aos usuários, os melhores serviços, o que gera competição entre as empresas deste setor de atividade. Com isso, essas empresas deverão realizar investimentos constantes para que possam se sustentar neste mercado, bem como, de acordo com as suas estratégias, expandir sua participação.

A análise da evolução das atividades de investimento das empresas deste setor torna-se relevante. Uma das bases informacionais, dos investimentos realizados pelas empresas deste setor, são aquelas apresentadas em seus Fluxos de Caixa. O Fluxo de Caixa constitui o movimento de entradas e saídas de caixa, bem como as variações no saldo dessa conta. Podese dizer que o Fluxo de Caixa é um instrumento utilizado com o objetivo de apurar os somatórios de ingressos e desembolsos financeiros da empresa em determinado momento. (ZDANOWICZ, 2004).

As maiorias das empresas apresentam dificuldade em reconhecer o cenário econômico-financeiro do seu negócio. A falta de planejamento e falhas na gestão financeira, muitas das vezes, complica o processo de tomada de decisão. Essa inexistência de planejamento e gestão financeira é um dos principais motivos para o fracasso empresarial. Sendo assim, saber se planejar financeiramente é essencial para poder se manter competitivo no mercado (GAZOLA, 2014).

Os gestores devem tomar suas decisões em curto prazo e, para que isso aconteça, precisam de um grupo de dados e informações confiáveis, reduzindo as chances de cometerem erros. Os relatórios de análise devem ser elaborados como se fossem dirigidos a leigos, ainda que não o sejam, isto é, sua linguagem deve ser inteligível por qualquer dirigente de nível médio de empresa (MATARAZZO, 2008).

Sem o fluxo de caixa fica quase impossível projetar e planejar-se financeiramente; sem orçamento (planejamento financeiro) é impossível ter uma administração sadia (MARION, 


\section{Contabilidade}

2012). Portanto, considera-se que o Fluxo de Caixa é um importante instrumento gerencial, que apoia o administrador, para as tomadas de decisões em uma organização.

Desta forma, este trabalho está direcionado a responder a seguinte questão: qual foi a evolução das atividades de investimento apresentadas no Fluxo de Caixa de empresas do setor de telecomunicações? Este estudo tem por objetivo verificar a evolução das atividades de investimento, apresentadas no Fluxo de Caixa, de empresas do setor de telecomunicações listadas na B3. Têm-se como hipótese teórica que os investimentos demonstrados no Fluxo de Caixa aumentaram, ao longo do período pesquisado, em todas as empresas.

Este artigo está dividido em cinco seções. A primeira seção é composta desta introdução. A segunda seção apresenta a plataforma teórica, composta de alguns aspectos acerca da administração financeira de empresas, da gestão do fluxo de caixa, e de estudos anteriores relacionados ao tema desta pesquisa. Na terceira seção são apresentados os procedimentos metodológicos utilizados para a coleta e análise dos dados. A seção de número quatro apresenta os resultados da pesquisa e sua análise e, por fim, a seção cinco traz as considerações finais do estudo.

\section{PLATAFORMA TEÓRICA}

Esta seção apresenta alguns aspectos relacionados com a administração financeira de empresas e da gestão do fluxo de caixa, bem como alguns estudos anteriores relacionados com o tema deste estudo, não com a finalidade de esgotar a discussão, mas a de propiciar alguns aspectos teóricos acerca do tema, para o adequado entendimento dos resultados da presente pesquisa.

\subsection{Alguns aspectos acerca do fluxo de caixa}

Administração Financeira diz respeito aos compromissos da empresa. Administradores financeiros administram as finanças de empresas de todos os gêneros, financeiras ou não, privadas ou públicas, grandes ou pequenas, com ou sem fins lucrativos. Segundo Gropelli e Nikbakht (2009), para serem bem-sucedidos, os administradores financeiros têm que se envolver com as mudanças que ocorrem constantemente nas finanças, ou seja, são responsáveis pelo reconhecimento e respostas aos fatores de mudanças em todos os ambientes, sejam eles privados, públicos ou financeiros.

Algumas pessoas acreditam que o objetivo dos proprietários é sempre a maximização do lucro. Para chegar ao propósito de maximização do lucro, o administrador financeiro 


\section{Contabilidade}

considera apenas aquelas decisões que se espera que trarão maior colaboração para a lucratividade da empresa (GITMAN, 2010). Logo, de acordo com Ross, Westerfield e Jordan (2010), o objetivo da administração financeira, numa sociedade por ações, é maximizar o valor corrente de cada ação existente.

É fundamental que o administrador financeiro saiba gerir corretamente os recursos alocados na massa patrimonial ativa da empresa, independentemente de seu porte (ZDANOWICZ, 2004). De acordo com Gitman (2010), a maioria das decisões empresariais são medidas em termos financeiros, logo, o administrador financeiro desempenha um papel crucial na operação da empresa. As pessoas de todas as áreas de responsabilidade da empresa necessitam interagir com o pessoal de finanças para realizar seu trabalho.

Gropelli e Nikbakht (2009) afirmam que, quando da tomada de decisões de investimentos, os administradores financeiros consideram os efeitos de alterações nas condições de demanda, ofertas e preços sobre o desempenho da empresa. O conhecimento do conteúdo desses aspectos ajuda os administradores a tomarem as decisões operacionais mais proveitosas. A decisão de investir ou não em uma empresa, passa pela análise da capacidade de ela gerar Fluxos de Caixa (CHING et al., 2010).

O Fluxo de Caixa é uma das ferramentas mais aplicadas pelo administrador financeiro na gestão empresarial. A administração financeira é a arte e a ciência de administrar os recursos financeiros para maximizar a riqueza dos acionistas (LEMES JUNIOR; CHEROBIM; RIGO, 2010). Sendo assim, pode-se dizer que todas as empresas deveriam aplicar um controle rígido de caixa.

Com a base de um fluxo de caixa projetado a empresa dispõe um importante instrumento aos administradores para a tomada de decisões. Para Zdanowicz (2004) o fluxo de caixa é o instrumento de programação financeira, que corresponde às estimativas de entradas e saídas de caixa em certo período projetado. A partir desta estimativa, a coordenação das finanças se torna mais precisa, visto que já em mãos o que irá receber e o que irá pagar em determinado período, conseguindo prever prováveis investimentos com as sobras, bem como a demanda de recursos quando existir déficit no caixa da empresa. $\mathrm{O}$ Quadro 1 apresenta algumas definições acerca do Fluxo de Caixa. 
Quadro 1: Algumas definições de fluxo de caixa

\begin{tabular}{|c|l|}
\hline Autor (ano) & \multicolumn{1}{c|}{ Definições } \\
\hline Assaf Neto (2009) & $\begin{array}{l}\text { Fluxo de Caixa são os recursos que transitam (entram e saem) pelo caixa em } \\
\text { determinado intervalo de tempo. }\end{array}$ \\
\hline Blatt (2001) & $\begin{array}{l}\text { Fluxo de Caixa nada mais é que a diferença entre o valor recebido menos o valor pago } \\
\text { em caixa, durante um determinado período do relatório financeiro. }\end{array}$ \\
\hline $\begin{array}{c}\text { Ross, Westerfield e } \\
\text { Jordan (2010) }\end{array}$ & $\begin{array}{l}\text { O Fluxo de Caixa é uma das informações financeiras mais importantes que podem ser } \\
\text { extraídas de demonstrações financeiras. Indica a diferença entre o número de dólares } \\
\text { recebidos e os que saíram da empresa. }\end{array}$ \\
\hline Silva (1996) & $\begin{array}{l}\text { Fluxo de Caixa é considerado um dos principais instrumentos de análise, propiciando } \\
\text { identificar o processo de circulação do dinheiro, pois, ele tem a capacidade de examinar } \\
\text { as entradas e saídas de dinheiro que transitaram pela empresa, assim como o que ainda } \\
\text { não aconteceu, mas que está projetado para o futuro. }\end{array}$ \\
\hline Pivetta (2004) & $\begin{array}{l}\text { Fluxo de Caixa representa a previsão, o controle e o registro de entradas e saídas } \\
\text { financeiras durante um determinado período, contendo informações sobre a vida } \\
\text { financeira da empresa. }\end{array}$ \\
\hline Zdanowicz (2004) & $\begin{array}{l}\text { O Fluxo de Caixa é o instrumento de programação financeira, que corresponde às } \\
\text { estimativas de entradas e saídas de caixa em certo período de tempo projetado. }\end{array}$ \\
\hline
\end{tabular}

Fonte: Elaborado pelos autores.

Alguns aspectos importantes percebidos através do Fluxo de Caixa, como a existência de concentração de pagamentos/recebimentos, sazonalidade nas vendas, necessidade e resultados das políticas de marketing e promoções, estrutura de custos/despesas fixa, necessidade da separação dos controles pessoais e da empresa, necessidade de uma remuneração pelo trabalho do empreendedor, efeitos dos tributos e a noção de passivos/obrigações (PIVETTA, 2004).

Conforme Zdanowicz (2004) o Fluxo de Caixa é o instrumento que permite ao administrador financeiro: planejar, organizar, coordenar, dirigir e controlar os recursos financeiros de sua empresa para um determinado período. Esse controle é vantajoso tanto quando a empresa está se desenvolvendo e ampliando seus negócios quanto na fase em que apresenta prejuízo, tornando possível a visualização de problemas que a estão levando ao prejuízo.

Cada empresa tem seu meio de projetar seu Fluxo de Caixa de maneira a tirar informações importantes com mais facilidade. Independente da especialidade de análise de cada empresa é importante que a Projeção de Fluxo de Caixa esteja separada em, no mínimo, três grandes grupos que vão simplificar a compreensão do que a empresa possui, o quanto ela ganha, o que ela gasta, quanto tem para investir e quando pode investir.

A Demonstração do Fluxo de Caixa (DFC) indica a origem de todas as entradas no caixa (disponibilidades), bem como a destinação de todo o dinheiro que saiu do caixa em determinado período (BORINELLI; PIMENTEL, 2010).

De acordo com o IBRACON (1999), Pronunciamento do Instituto dos Auditores Independentes do Brasil (IBRACON nº 20 de 30/04/1999, NPC 20), a Demonstração dos 


\section{Contabilidade}

Fluxos de Caixa refletirá as transações de caixa oriundas: a) das atividades operacionais; b) das atividades de investimentos; e c) das atividades de financiamentos. Atividades de investimentos: compreendem as transações com os ativos financeiros, as aquisições ou vendas de participações em outras entidades e de ativos utilizados na produção de bens ou prestação de serviços ligados ao objeto social da Entidade. As atividades de investimentos não compreendem a aquisição de ativos com o objetivo de revenda.

Embora a DFC seja considerada um instrumento de avaliação de liquidez da empresa, o formato de apresentação da DFC mais difundido (até por motivos legais) tem sido aquele por atividades, que contempla as atividades operacionais, de financiamento e de investimento (BRAGA; MARQUES, 2001).

Considerando que as atividades operacionais geralmente incluem a produção e entrega de bens e fornecimento de serviços, essas atividades sofrem efeitos diretamente no resultado líquido, em decorrência do fluxo de caixa (BRAGA; MARQUES, 2001).

Devido à natureza da transação, o formato da Demonstração do Fluxo de Caixa foi segregado em três blocos distintos, sendo: Fluxos de caixa das atividades operacionais; Fluxos de Caixa das atividades de investimento; Fluxos de Caixa das atividades de Financiamento. Borinelli e Pimentel (2010) apontam que esta segregação permite ao usuário avaliar o impacto de tais atividades na posição financeira e patrimonial da empresa.

As transações operacionais são as mais importantes, já que interferem no lucro líquido e nas contas circulantes do Balanço (CHING et al., 2010). O fluxo de caixa operacional mostra a eficiência de uma empresa na geração de caixa, ou seja, considerando apenas as entradas e saídas de caixa (BORINELLI; PIMENTEL, 2010).

As atividades de investimento contemplam aquisição e venda de ativos de longo prazo e outros investimentos que não estejam incluídos nos equivalentes de caixa; tal fato indica se a empresa investiu e em que itens ou se ela faz caixa vendendo parte do ativo permanente (BORINELLI; PIMENTEL, 2010).

O Comitê de Pronunciamentos Contábeis (CPC 03, item 7), elucida que as atividades de financiamento são aquelas que resultam em mudanças no tamanho e na composição do capital próprio e no endividamento da entidade, não classificadas como atividade operacional. O próximo item apresenta alguns estudos anteriores relacionados ao tema (COMITE DE PRONUNCIAMENTOS CONTÁBEIS, 2010). 


\section{Contabilidade}

\subsection{Estudos anteriores}

Alguns estudos anteriores foram discutidos com relação a importância do fluxo de caixa as organizações. No estudo de Pivetta (2004) sobre fluxo de caixa, pode-se constatar a sua menor complexidade diante as Demonstrações de Origens e Aplicações, facilitando a todos usuários e até mesmos os que não possui conhecimento a termos técnicos. Observa-se também que o fluxo de caixa nada mais é que a economia do tempo nas entradas e saídas de dinheiro da empresa se tornando de fácil integração ao setor financeiro. Contudo conclui-se que o fluxo de caixa é num todo um instrumento gerencial capaz de demonstrar a importância nas Demonstrações do Fluxo de caixa principalmente para as pequenas e médias empresas.

O estudo de Toledo Filho, Oliveira e Spessatto (2010) evidencia o fluxo de caixa e as técnicas administrativas como principal instrumento de controle gerencial para tomada de decisão nas microempresas apresentando eficácia na gestão financeira das empresas, permitindo ao administrador planejar, organizar, coordenar, dirigir e controlar os recursos financeiros para um determinado período, influenciando o processo de tomada de decisão. Conclui-se que apesar de ser um instrumento conhecido pela maioria, ainda são poucos os administradores que implantam o fluxo de caixas em suas empresas desconhecendo o processo de administração e manutenção dos recursos financeiros.

A pesquisa realizada por Gimenes, Francisco e Silva (2011) reforça a importância da utilização dos demonstrativos de fluxo de caixa cujo mecanismo é indispensável a tomada de decisões, explicitaram também que o fluxo de caixa é o instrumento que permite total controle da gestão financeira da empresa e que sua usabilidade se torna indispensável tendo em vista o mercado competitivo.

O estudo de Erbano, et al. (2014), destaca que o fluxo de caixa é um instrumento que permite ao administrador o planejamento e controle da organização em determinado período. Permitiu-se concluir que os estudos voltados ao crescimento da empresa e suas ferramentas administrativas ajudem o processo de tomada de decisão, e ferramentas essas o fluxo de caixa indispensável para medição da situação da organização.

O estudo de Schmeier e Fank (2016) apresentou informações sobre o funcionamento e os métodos da demonstração do fluxo de caixa, enfatizando a sua importância, e conclui essa relevância ao demonstrar a saúde financeira da empresa advêm a partir destas análises e para que se tenha uma resposta clara sobre o investimento e estágio atual da empresa. 


\section{Contabilidade}

\section{PROCEDIMENTOS METODOLÓGICOS}

Inicialmente foi realizada pesquisa bibliográfica, acerca do tema, na literatura existente e em periódicos científicos nacionais e internacionais, para a elaboração da plataforma teórica. Esta pesquisa também pode ser caracterizada como descritiva, por apresentar dados das empresas de forma que foi possível descrever as características dos elementos relacionados às atividades de investimentos no Fluxo de Caixa.

Foram selecionadas para a pesquisa, as empresas do setor de telecomunicações listadas na B3 no ano de 2016. As empresas selecionadas foram as seguintes:

- Algar Telecom S. A.;

- Jerussati Participações S.A;

- JPSP Investimentos e Participações S.A;

- Oi S.A;

- Telebrás S. A.;

- Telefônica Brasil S.A; e

- Tim Participações S. A.

Foram coletados, no site da B3 e das empresas, as Demonstrações do Fluxo de Caixa dos anos de 2013, 2014 e 2015, com a finalidade de identificar os valores das atividades de investimento realizadas pelas empresas no período definido.

Após a coleta dos valores monetários das atividades de investimento constantes nos Fluxos de Caixa das empresas selecionadas para o estudo, foi elaborada a tabulação dos dados, e a elaboração de tabelas e figura, para a realização da análise da evolução das atividades de investimentos realizadas pelas empresas. Esta fase da pesquisa foi importante, pois tornou possível a análise de cada empresa durante o período, através da Análise Horizontal, bem como a comparação entre as empresas, através da Análise Vertical. Os resultados serão apresentados com dados absolutos e relativos, em figura e tabelas. 


\section{Contabilidade}

\section{RESULTADOS DO ESTUDO}

Os dados das empresas do setor de telecomunicações, listadas na B3, foram obtidos das suas respectivas Demonstrações dos Fluxos de Caixa, disponibilizadas no site da B3, no período de 2013 até 2015. Foram coletados os valores referentes às atividades de investimentos constantes em seus Fluxos de Caixa.

A análise dos resultados do estudo tem como objetivo verificar a evolução das atividades de investimento constantes no Fluxo de Caixa, por considerá-las como aqueles efetivamente realizados, por haver o desembolso de recursos financeiros para determinadas atividades de investimento, e que poderão gerar retorno financeiro e que, provavelmente, poderão aumentar as entradas futuras de caixa. A Figura 1 apresenta os valores das atividades de investimento realizadas pelas empresas, constantes nos Fluxos de Caixa dos anos de 2013 até 2015.

Analisando-se a conta Caixa Líquido das atividades de Investimento, constante no Fluxo de Caixa das empresas do setor de Telecomunicações, listadas na B3 nos anos de 2013, 2014 e 2015, destaca-se que, em valores absolutos, as empresas Telefônica, Oi e Tim foram monetariamente os maiores, em comparação com as demais empresas, em todo o período analisado. As empresas Telefônica Brasil S. A. e Oi S. A. foram aquelas com as maiores atividades de investimentos constantes em seus Fluxos de Caixa, no ano de 2015.

Pode-se observar a evolução dos valores das atividades de investimento de cada empresa, com isso, destaca-se que a empresa Telefônica apresentou aumento crescente durante o período, ou seja, os investimentos no ano de 2014 foram superiores aos do ano de 2013, e de 2015 superiores ao do ano de 2014; os valores das atividades de investimento desta empresa, no ano de 2015 foram praticamente o dobro, se comparado com o ano de 2014. 


\section{Contabilidade}

Figura 1 - Caixa Líquido das atividades de Investimento

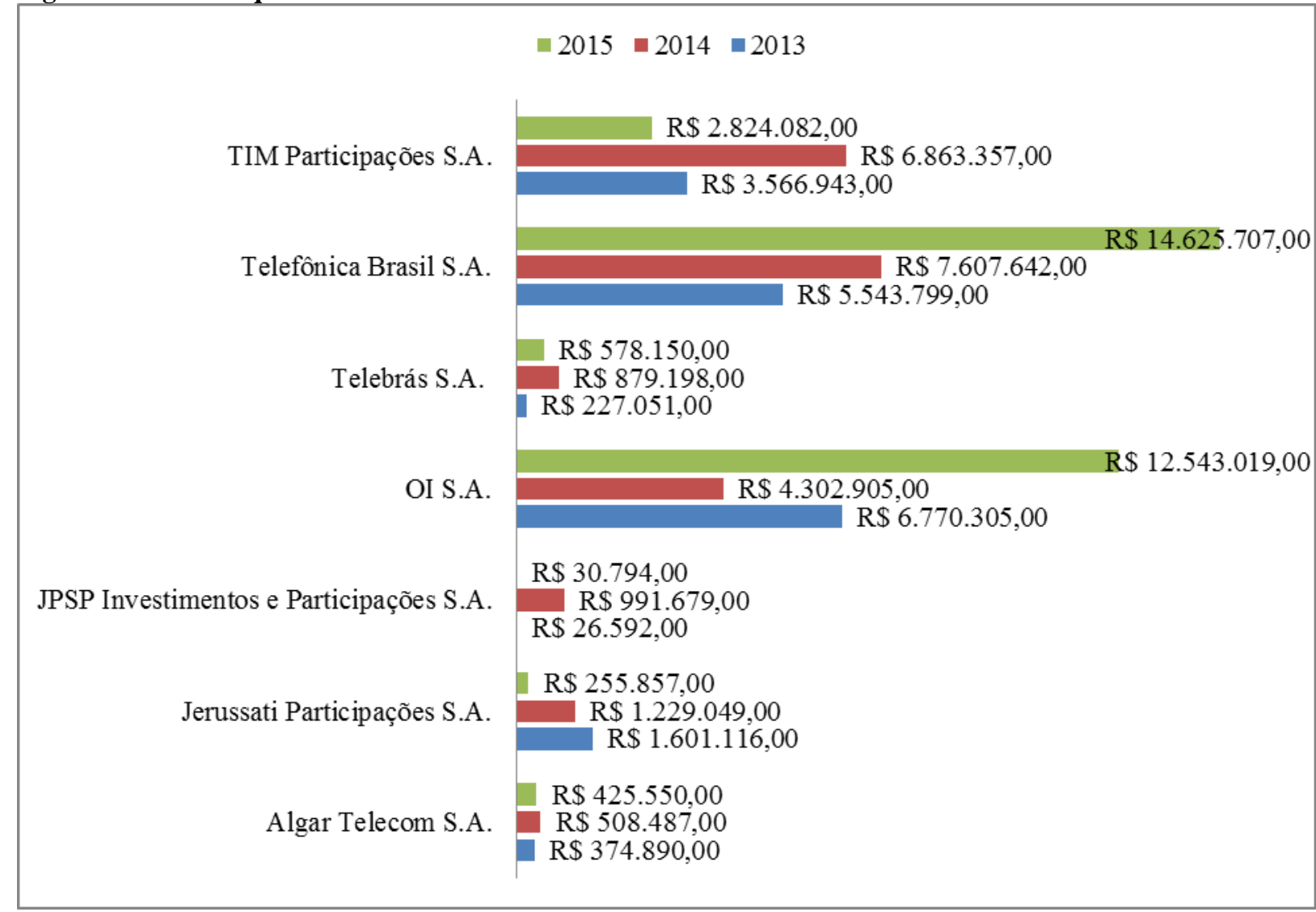

Fonte: Dados da pesquisa.

A empresa Oi S. A. apresentou um volume monetário nas atividades de investimento, no ano de 2013, superiores aos da Telefônica no mesmo período, porém, seus investimentos diminuíram no ano de 2014, correspondente a uma redução de 36,44\% das atividades de investimentos constantes no Fluxo de Caixa. Por outro lado, os valores no ano de 2015 foram inferiores somente para os da Telefônica, mas corresponderam a um aumento de 291,5\% em relação ao ano de 2014.

Com relação à evolução das atividades de investimentos apresentadas no Fluxo de Caixa da empresa Tim S. A., destaca-se que a empresa praticamente dobrou seus valores monetários, comparando-se os anos de 2013 e 2014, porém, no ano de 2015, os valores foram consideravelmente inferiores aos do ano de 2014, correspondendo a 41,1\% dos valores dos investimentos de 2014.

Foi possível observar que a empresa Jerussati Participações S. A. apresentou redução das atividades de investimento apresentadas em seu Fluxo de Caixa, em todos os anos da pesquisa, ou seja, os valores no ano de 2014 foram menores do que os de 2015, e de 2013 menores que os apresentados no ano de 2014. 
$\mathrm{Na}$ Análise Horizontal, observa-se que os valores adicionados às contas de demonstrações financeiras, evidenciando assim o percentual de cada conta correlacionado ao um valor base. A Tabela 1 apresenta a Análise Horizontal, para o período de 2013 até 2015, das empresas selecionadas para a pesquisa, acerca do Caixa Líquido das atividades de investimento, constantes em seus Fluxos de Caixa.

Tabela 1 - Análise Horizontal das empresas selecionadas

\begin{tabular}{l|r|r|r|r|r|r}
\hline \multicolumn{1}{c|}{ Empresas } & $\mathbf{2 0 1 3}(\mathbf{R} \mathbf{)}$ & \multicolumn{1}{c|}{$\mathbf{A H}$} & $\mathbf{2 0 1 4}(\mathbf{R} \mathbf{)}$ & \multicolumn{1}{c|}{$\mathbf{A H}$} & \multicolumn{1}{c|}{$\mathbf{2 0 1 5}(\mathbf{R} \mathbf{)}$} & \multicolumn{1}{c}{$\mathbf{A H}$} \\
\hline Algar Telecom S.A. & $374.890,00$ & $100 \%$ & $508.487,00$ & $135,64 \%$ & $425.550,00$ & $113,51 \%$ \\
\hline Jerussati Particip. S.A. & $1.601 .116,00$ & $100 \%$ & $1.229 .049,00$ & $76,76 \%$ & $255.857,00$ & $15,98 \%$ \\
\hline JPSP Particip. S.A. & $26.592,00$ & $100 \%$ & $991.679,00$ & $3729,24 \%$ & $30.794,00$ & $115,80 \%$ \\
\hline Oi S.A. & $6.770 .305,00$ & $100 \%$ & $4.302 .905,00$ & $63,56 \%$ & $12.543 .019,00$ & $185,27 \%$ \\
\hline Telebrás S.A. & $227.051,00$ & $100 \%$ & $879.198,00$ & $387,22 \%$ & $578.150,00$ & $254,63 \%$ \\
\hline Telefônica Brasil S.A. & $5.543 .799,00$ & $100 \%$ & $7.607 .642,00$ & $137,23 \%$ & $14.625 .707,00$ & $263,82 \%$ \\
\hline Tim Particip. S.A. & $3.566 .943,00$ & $100 \%$ & $6.863 .357,00$ & $192,42 \%$ & $2.824 .082,00$ & $79,17 \%$ \\
\hline $\begin{array}{l}\text { Total do Caixa Liq. Ativ. } \\
\text { Investimento }\end{array}$ & $\mathbf{1 8 . 1 1 0 . 6 9 6 , 0 0}$ & $\mathbf{1 0 0 \%}$ & $\mathbf{2 2 . 3 8 2 . 3 1 7 , 0 0}$ & $\mathbf{1 2 3 , 5 9 \%}$ & $\mathbf{3 1 . 2 8 3 . 1 5 9 , 0 0}$ & $\mathbf{1 7 2 , 7 3 \%}$ \\
\hline
\end{tabular}

Fonte: Dados da pesquisa.

Realizando-se a análise horizontal, foi possível destacar que, em relação ao ano base (2013), as empresas JPSP (3.729,2\%), Telebrás (387,2\%), Telefônica (137,2\%), Tim $(192,4 \%)$ e Algar $(135,6 \%)$ foram as empresas que apresentaram investimentos superiores no ano de 2014 comparados com o ano base (2013). Por outro lado, as empresas Jerussati $(76,8 \%)$ e Oi $(63,6 \%)$ foram as empresas que realizaram investimentos, no ano de 2014, inferiores aos do ano base.

Comparando-se os resultados do ano de 2015 com o ano base (2013), destaca-se a evolução dos investimentos das empresas Telefônica (263,8\%), Telebrás (254,6\%), Oi (185,3\%), JPSP $(115,8 \%)$ e Algar $(113,5 \%)$. Já as empresas que apresentaram declínio dos investimentos neste mesmo período foram a Tim $(79,2 \%)$ e Jerussati $(16 \%)$.

A Análise Vertical evidencia a importância de cada conta dentro da demonstração realizando o comparativo entre os padrões ligando a situação da empresa em períodos anteriores, podendo demonstrar oscilações não usuais. A Tabela 2 apresenta os resultados da pesquisa acerca da Análise Vertical, utilizando-se como base de dados os valores presentes no Caixa Líquido das atividades de investimento das empresas selecionadas, no período de 2013 até 2015.

Realizando-se a análise vertical no ano de 2013, destaca-se que os maiores percentuais em relação ao total do Caixa Líquido das atividades de Investimento das empresas 


\section{Contabilidade}

selecionadas, foram das empresas Oi $(37,4 \%)$ e Telefônica $(30,6 \%)$, e os menores foram das empresas JPSP $(0,15 \%)$ e Telebrás $(1,25 \%)$.

Tabela 2 - Análise Vertical das empresas selecionadas

\begin{tabular}{l|r|r|r|r|r|r}
\hline \multicolumn{1}{c|}{ EMPRESAS } & $\mathbf{2 0 1 3}(\mathbf{R} \mathbf{)}$ & \multicolumn{1}{c|}{$\mathbf{A V}$} & $\mathbf{2 0 1 4}(\mathbf{R} \mathbf{)}$ & \multicolumn{1}{c|}{$\mathbf{A V}$} & \multicolumn{1}{c|}{$\mathbf{2 0 1 5}(\mathbf{R} \mathbf{)}$} & \multicolumn{1}{c}{$\mathbf{A V}$} \\
\hline Algar Telecom S.A. & $374.890,00$ & $2,07 \%$ & $508.487,00$ & $2,27 \%$ & $425.550,00$ & $1,36 \%$ \\
\hline Jerussati Particip. S.A. & $1.601 .116,00$ & $8,84 \%$ & $1.229 .049,00$ & $5,49 \%$ & $255.857,00$ & $0,82 \%$ \\
\hline JPSP Particip. S.A. & $26.592,00$ & $0,15 \%$ & $991.679,00$ & $4,43 \%$ & $30.794,00$ & $0,10 \%$ \\
\hline Oi S.A. & $6.770 .305,00$ & $37,38 \%$ & $4.302 .905,00$ & $19,22 \%$ & $12.543 .019,00$ & $40,10 \%$ \\
\hline Telebrás S.A. & $227.051,00$ & $1,25 \%$ & $879.198,00$ & $3,93 \%$ & $578.150,00$ & $1,85 \%$ \\
\hline Telefônica Brasil S.A. & $5.543 .799,00$ & $30,61 \%$ & $7.607 .642,00$ & $33,99 \%$ & $14.625 .707,00$ & $46,75 \%$ \\
\hline Tim Participações S.A. & $3.566 .943,00$ & $19,70 \%$ & $6.863 .357,00$ & $30,66 \%$ & $2.824 .082,00$ & $9,03 \%$ \\
\hline $\begin{array}{l}\text { Total do Caix Liq. Ativ. } \\
\text { Investimento }\end{array}$ & $\mathbf{1 8 . 1 1 0 . 6 9 6 , 0 0}$ & $\mathbf{1 0 0 \%}$ & $\mathbf{2 2 . 3 8 2 . 3 1 7 , 0 0}$ & $\mathbf{1 0 0 \%}$ & $\mathbf{3 1 . 2 8 3 . 1 5 9 , 0 0}$ & $\mathbf{1 0 0 \%}$ \\
\hline
\end{tabular}

Fonte: Dados da pesquisa.

No ano de 2014, pode-se verificar que as empresas Telefônica (34\%) e Tim (30,6\%) foram as empresas que tiveram os maiores percentuais em relação ao Caixa Líquido das atividades de Investimento das empresas selecionadas. Por outro lado, as empresas com os menores percentuais em relação ao total foram a Algar (2,3\%) e Telebrás $(3,9 \%)$.

Considerando-se os percentuais em relação ao Caixa Líquido das atividades de Investimento das empresas selecionadas do ano de 2015, pode-se identificar que as empresas Telefônica $(46,8 \%)$ e Oi $(40,1 \%)$ foram aquelas que tiveram os maiores percentuais em relação ao total, e as empresas que tiveram os menores percentuais foram a JPSP $(0,1 \%)$ e a Algar (1,4\%).

\section{CONSIDERAÇÕES FINAIS}

Este estudo teve como objetivo verificar a evolução das atividades de investimento, apresentadas no Fluxo de Caixa, de empresas do setor de telecomunicações listadas na B3, considerando-se, como hipótese teórica, que os investimentos demonstrados no Fluxo de Caixa aumentaram, em todas as empresas, no período pesquisado, que correspondeu aos anos de 2013 até 2015.

Observando-se o exposto pelos dados das empresas de telecomunicações, pode-se destacar a importância da Análise Vertical e Horizontal dos Fluxos de Caixa de investimentos das empresas; pode-se visualizar nos últimos períodos, as tendências e comportamentos adotados. A relevância destas informações expõe o direcionamento por parte dos gestores e principalmente transmitem a evidenciação da saúde financeira das organizações. 


\section{Contabilidade}

Em relação aos valores das atividades de investimento apresentadas nos Fluxos de Caixa das empresas selecionadas, pode-se inferir que os maiores investimentos são realizados por poucas empresas, neste caso, destacam-se as empresas Telefônica, Oi e Tim; as demais empresas da pesquisa, considera-se que seus investimentos foram incipientes, comparados com aquelas que apresentaram os maiores gastos com investimentos.

A respeito da evolução das empresas ao longo do tempo, acerca das atividades de investimento, através da Análise Horizontal, pode-se inferir que as empresas Telefônica, Telebrás e Oi foram as que apresentaram as maiores evoluções relativas (\%), em comparação com as demais empresas selecionadas.

Acerca da Análise Vertical, verificou-se a evolução dos investimentos do setor, pois a cada ano pesquisado os valores totais aumentaram. Pode-se inferir que as empresas estão aumentando seus gastos em atividades de investimento, mostrados em seus Fluxos de Caixa. Isso demonstra o interesse pela evolução dos serviços prestados aos consumidores, bem como uma necessidade de atuar de forma competitiva em um mercado de acirrada concorrência.

Em relação à hipótese teórica, pode-se inferir que, apesar da evolução total das atividades de investimentos, apenas duas empresas apresentaram evolução das atividades de investimento, ou seja, valores superiores no último ano da pesquisa superiores aos demais anos. Portanto, mostra-se que esta hipótese não se comprova com os resultados da pesquisa.

Ressalta-se outro aspecto, que é da avaliação de um segmento de atividade que impacta praticamente no cotidiano da maioria da população brasileira, que depende da comunicação a todo o momento, e as empresas referidas são as administradoras e prestadoras destes serviços. $\mathrm{O}$ aspecto de caracterização de investimentos pode ser um reflexo com que cada organização prioriza as melhorias no setor.

O referido estudo indica que novas análises sobre esta temática se fazem necessárias, visto que o período de análise abrange a apenas os três anos mais recentes da data da pesquisa; recomenda-se um estudo mais amplo, considerando os períodos anteriores ao ano de 2013. Recomenda-se também realizar estudos relacionados ao objetivo do presente estudo, em outros setores de empresas.

\section{REFERÊNCIAS}

ASSAF NETO, A. Curso de administração financeira. São Paulo: Atlas, 2009.

BLATT, A. Estrutura e avaliação das demonstrações financeiras e contábeis. São Paulo: Makros Books, 2001. 
BORINELLI, M. L.; PIMENTEL, R. C. Curso de contabilidade para gestores, analistas e outros profissionais. São Paulo: Atlas, 2010.

BRAGA, R.; MARQUES, J. A. V. C. Avaliação da liquidez das empresas através da análise da demonstração dos fluxos de caixa. Revista de Contabilidade \& Finanças, v. 14, n. 25, 2001.

CHING, H. Y.; MARQUES, F.; PRADO, L. Contabilidade e Finanças para não especialistas. $3^{\text {a }}$ ed. São Paulo: Pearson, 2010.

COMITÊ DE PRONUNCIAMENTOS CONTÁBEIS. Pronunciamento técnico CPC 03: Demonstração dos Fluxos de Caixa. Comitê de Pronunciamentos Contábeis, 2010.

ERBANO, B. L.; THEISEN, D. G.; VEBER, E. E.; SOUZA, M. E. S.; SOUZA, A.; APEL, R. Fluxo de caixa. Revista Maiêutica, v. 1, n. 1, 2014.

GAZOLA, D. J. Planejamento estratégico: uma proposta de elaboração para a cooperativa da agricultura familiar - Cooperfamília. Trabalho de Conclusão de Curso de Ciências Contábeis da Universidade do Extremo Sul Catarinense - UNESC, 2014.

GIMENES, A. A.; FRANCISCO, F. D.; SILVA, G.; Fluxo de caixa. III Encontro Científico e Simpósio de Educação da Unisalesiano, 2011.

GITMAN, L. J. Princípios de administração financeira. São Paulo: Saraiva, 2010.

GROPELLI, A. A.; NIKBAKHT, E. Administração financeira. São Paulo: Saraiva, 2009.

IBRACON. Pronunciamento n. 20 de 30/04/1999, NPC 20. Instituto dos Auditores Independentes do Brasil - IBRACON, 1999.

LEMES JUNIOR, A. B.; CHEROBIM, A. P. M. S.; RIGO, C. M. Administração financeira: princípios, fundamentos e práticas brasileiras. Rio de Janeiro: Campus, 2010.

MARION, J. C. Análise das demonstrações contábeis. São Paulo: Atlas, 2012.

MATARAZZO, D. C. Análise financeira de balanços: abordagem gerencial. São Paulo: Atlas, 2008.

PIVETTA, G. A utilização do fluxo de caixa nas empresas: um modelo para a pequena empresa. Revista Eletrônica de Contabilidade, v. 1, n. 2, 2004.

ROSS, S. A.; WESTERFIELD, R. W.; JORDAN, B. D. Princípios de administração financeira. São Paulo: Atlas, 2010.

SCHMEIER, R.; FANK, L. O.; Fluxo de caixa. III Simpósio de Agronomia e Tecnologia em Alimentos, 2016.

SILVA, J. P. Análise financeira nas empresas. São Paulo: Atlas, 1996. 
TOLEDO FILHO, J. R.; OLIVEIRA, E. L.; SPESSATTO, G. Fluxo de caixa como instrumento de controle gerencial para tomada de decisão: um estudo realizado em microempresas. Revista de Contabilidade do Mestrado em Ciências Contábeis da UERJ, v. 15, n. $2,2010$.

ZDANOWICZ, J. E. Fluxo de caixa: uma decisão de planejamento e controle financeiro. 10a ed. Porto Alegre: Sagra Luzzatto, 2004. 